ISSN: 1679-3013

D.O.I.: 10.5914/to.2011.0054

\title{
SÍNTESE DA ANÁLISE COMPARATIVA ENTRE OS PORTOS DO RECIFE E DE SUAPE: DESAFIOS PARA A GESTÃO AMBIENTAL
}

\author{
Maria Evelina Menezes de SÁ ${ }^{\mathbf{1}}$ \\ Alexandre de Carvalho LEAL NETO² \\ Lourdinha FLORENCIO ${ }^{3}$
}

Recebido em: 01/06/2010

Aceito em: $17 / 05 / 2011$

\begin{abstract}
RESUMO
Este trabalho trata da abordagem da Gestão Ambiental Portuária (GAP) no estado de Pernambuco e está centrado na área de estudo nos portos do Recife e de SUAPE levando-se em consideração suas características ambientais e operacionais bem distintas. Por outro lado, os estudos demonstraram que os desafios da GAP são muitos em todos os portos do mundo e não apenas nos portos aqui analisados. No Brasil, mesmo depois da Lei 8.630/93 conhecidas como a Lei de Modernização dos Portos, que já completou mais de 15 anos, os diversos atores envolvidos ainda não conseguiram identificar com clareza as suas competências para a implementação de uma Gestão Ambiental Portuária eficaz (PORTO; TEIXEIRA, 2002). Com este estudo constatou-se que os portos do Recife e de SUAPE estão se adaptando a esta nova realidade de gestão ambiental e diante desta visão formulou-se a seguinte questão central de pesquisa: "Quais as dificuldades encontradas pelos gestores dos portos do Recife e de SUAPE para atender às exigências da legislação ambiental?". Com essa perspectiva, o presente estudo teve como objetivo diagnosticar as características das conformidades ambientais específicas dos portos do Recife e de SUAPE identificando os procedimentos adotados por seus gestores para atender aos requisitos e exigências legais desta gestão. De forma específica objetivou-se: contribuir com subsídios para os gestores dos portos estudados na operacionalização da gestão ambiental; realizar análise comparativa dos procedimentos adotados pelos dois portos para a gestão ambiental; e evidenciar dados que venham promover trabalhos científicos em aperfeiçoamento aos sistemas de gestão ambiental portuária. Por meio deste estudo, os autores procuraram oferecer subsídios para equacionar os desafios associados à gestão ambiental portuária (e destes dois portos em particular) e as formas de ultrapassar as dificuldades que surgem nesse processo. Acrescenta-se ao estudo a recomendação de que a gestão ambiental seja abordada de forma estratégica com o desenvolvimento das Agendas Ambientais Institucionais e/ou Locais.
\end{abstract}

Palavras-chave: Gestão ambiental portuária, Procedimentos de gestão, Portos do Recife e SUAPE, Agenda Ambiental Portuária.

\section{SUMMARY OF COMPARATIVE ANALYSIS BETWEEN THE PORT OF RECIFE AND SUAPE: CHALLENGES FOR ENVIRONMENTAL MANAGEMENT}

\section{ABSTRACT}

The challenges faced by Port Environmental Management are considerable in every port in Brazil and worldwide. Within this context, the ports of Recife and SUAPE are getting adapted to this new trend of modernization. Therefore, the present study aims to identify

Contato: $1^{1}$ : SUAPE: Km 10 - Rod. PE-60 - Engenho Massangana - Ipojuca - Pernambuco.e-mail: evetrab@gmail.com.

2: CDRJ: Companhia Docas do Rio de Janeiro, Rua Acre no 21, Sala 801, Rio de Janeiro, RJ e-mail: aleal@netbotanic.com.br

3 : UFPE: Universidade Federal de Pernambuco, Departamento de Engenharia Civil, Av. Arquitetura s/n Cidade Universitária, Recife, PE.

e-mail: flor@ufpe.br 
SÁ, M. E. M.; LEAL NETO, A. de C.; Florencio, L. Síntese da análise comparativa entre os portos do Recife e de SUAPE: desafios para a gestão ambiental.

the specific characteristics of each of these two ports, the adopted procedures to meet the requisites and legal requirements as well as the difficulties to implement a Port Environmental Management programme. In order to achieve these objectives, the research was conducted upon a qualitative approach, using an interactive methodology that combined the hermeneutic dialectic circle technique on data collection to the hermeneutic dialectic approach on data analysis. It was pointed out that both ports present very distinct environmental and operational characteristics. The research results demonstrate that the managers of Recife and SUAPE ports are committed to meet the legal requirements and environmental requisites although there are political and technical constraints, as well as difficulties in investment priority decision-making. The research study recommends that the approach to Environmental Management should be strategically tuned with the development and implementation of institutional and/or local environmental agendas. It is expected that this study present solid subsidies in order to overcome the identified challenges in the environmental management field at both ports, thus contributing for their upgrading.

Keywords: Port Environmental Management, Management Procedures, Recife and SUAPE Ports, Environmental Management Agenda.

\section{INTRODUÇÃO}

O tema da gestão ambiental portuária despertou interesse devido a sua importância para o estado de Pernambuco, quanto à dimensão dos riscos ecológico regional e locais para o ecossistema da área de influência direta dos portos do Recife e de Suape.

Além de existir também carência de informações sistematizadas e disponíveis no Estado para subsidiar o monitoramento ambiental e a implementação do Sistema Integrado de Gestão Ambiental Portuária.

Justifica-se a importância dessa temática pelo fato de que os portos do Recife e de Suape possuem características ambientais e operacionais bem distintas.

Segundo Kitzmann e Asmus (2006), a implementação de reformas portuárias iniciadas a partir da Lei no 8.630/93 traz muitos desafios. Entre eles, o da gestão ambiental, ainda não adequadamente incorporada ao sistema portuário brasileiro.

As iniciativas de gestão ambiental no âmbito nacional não fazem parte do setor de planejamento portuário, levando a ações desarticuladas e reativas, resultado da visão equivocada de alguns que consideram a regulamentação ambiental um fator que ameaça a competitividade das empresas. Entretanto, Kitzmann e Asmus (2006) defendem que a adequação às normas ambientais traz oportunidades de melhoria para o negócio portuário.

Nesse contexto portuário nacional de mudança, a Agência Nacional de Transportes Aquaviários (ANTAQ) foi criada em $2001 \mathrm{com}$ a finalidade de regular, supervisionar e fiscalizar as atividades de prestação de serviços da exploração da infraestrutura portuária.

Os portos fazem parte de um mercado fortemente globalizado, onde as ações individuais podem comprometer as relações comerciais pelo não cumprimento às determinações legais da área ambiental ou de segurança. Para eles, o desenvolvimento de um sistema de gestão ambiental, apesar das dificuldades, tem se apresentado como uma forma de partir definitivamente para uma gestão responsável e competitiva.

Ao se referir à gestão ambiental, Seiffert (2007), apontou a diferença entre gestão e gerenciamento ambiental, esclarecendo que o gerenciamento ambiental, na verdade, é parte integrante da gestão ambiental, ou seja, gestão ambiental é mais ampla, pressupõe uma política, o planejamento e o próprio gerenciamento ambiental.

Esta realidade não ocorre apenas no Brasil; mesmo os portos de países desenvolvidos têm problemas quanto à gestão ambiental. Nos portos europeus, por exemplo, a definição de práticas ambientais para portos é recente. O "Código de Práticas Ambientais" da Organização Européia de Portos Marítimos - European Sea Ports 
SÁ, M. E. M.; LEAL NETO, A. de C.; Florencio, L. Síntese da análise comparativa entre os portos do Recife e de SUAPE: desafios para a gestão ambiental.

Organization (ESPO, 2005), apesar de ter sido publicado em 1994, foi adotado após sua revisão apenas em 2003.

Esse código estabelece a política ambiental, adota a legislação ambiental, além de definir práticas que auxiliam os administradores portuários na implementação dos instrumentos de gestão ambiental. Fazem parte da ESPO mais de 800 portos de 23 países europeus, tornando-a estratégica na interface entre os portos marítimos e as demais instituições da União Européia para atingir o objetivo da sustentabilidade.

Os portos do Recife e de Suape a exemplo dos demais portos brasileiros e internacionais ainda estão se adaptando a esta nova realidade de regulação na gestão ambiental e diante desta questão formulou-se a seguinte questão central de pesquisa: Quais as dificuldades encontradas pelos gestores dos portos do Recife e de Suape para atender às exigências da legislação ambiental?

Para responder a esta questão central e aos objetivos do estudo foi realizada uma pesquisa junto aos profissionais envolvidos na Gestão Ambiental dos portos do Recife e de Suape e uma análise comparativa entre os procedimentos adotados por seus gestores.

A pesquisa foi realizada dentro de uma abordagem qualitativa, utilizando-se a metodologia interativa, visando facilitar o entendimento dos dados coletados. Dessa forma, com a metodologia interativa foi possível analisar e comparar as características da gestão ambiental portuária na área de estudo nas três fases detalhadas na metodologia: na pré-análise, na exploração do material e no tratamento dos resultados.

Os resultados encontrados nesta pesquisa contribuem para o gerenciamento ambiental dos dois portos e podem subsidiar a identificação de ações para serem utilizadas como instrumentos de gestão ambiental estadual evidenciando-se que esses portos, apesar de complementares, são ao mesmo tempo concorrentes.

A pesquisa realizada oferece ainda subsídios para ajudar as administrações portuárias a implementarem suas Agendas Ambientais Portuárias como instrumento de planejamento participativo, contribuindo para que os portos estudados atinjam o objetivo comum de segurança ambiental e vençam os desafios e as dificuldades para a implementação da Gestão Ambiental Portuária eficaz.

\section{ÁREA DE ESTUDO}

O Porto do Recife está localizado ao longo da margem Atlântica da Ilha do Recife, entre as desembocaduras dos rios Capibaribe, Jequiá, Tejipió e Jordão ao sul e a desembocadura do rio Beberibe ao norte, na região centro-leste da cidade e próximo ao centro comercial. Possui uma área de $3.251,624$ ha., incluindo a área de fundeio. 0 ponto de referência do porto é o farol de Recife (Farol do Picão), localizado no quebraondas principal.

O porto está separado do oceano Atlântico por um molhe artificial de pedras e de blocos de concreto construído por sobre um dique natural de recifes de arenito calcário e pelo extenso quebra-ondas, localmente conhecido como molhe do inglês, que guarda a sua principal entrada.

O acesso das embarcações ao Porto do Recife pode ocorrer por dois canais naturais, mas devido ao assoreamento, apenas o canal sul, com uma faixa de aproximadamente $260 \mathrm{~m}$ de largura e cerca de 3,4 km de comprimento e profundidade mínima de $10,00 \mathrm{~m}$, continua sendo utilizado por navios (OLIVEIRA FILHO, 2008).

O canal norte possui cerca de $1 \mathrm{~km}$ de extensão e profundidade de $6,5 \mathrm{~m}$. A área de fundeio externo para navios de grande e pequeno porte ou de quarentena se localiza em torno do ponto de coordenadas Lat.: 08003'08"S e Long.: 34051'02"W situado a cerca de 0,8 milhas a SSE do farol de Recife, alongando-se na direção SE, não havendo restrição quanto ao número de navios que podem fundear (ENGEVIX, 1987). 
SÁ, M. E. M.; LEAL NETO, A. de C.; Florencio, L. Síntese da análise comparativa entre os portos do Recife e de SUAPE: desafios para a gestão ambiental.

O porto do Recife teve sua origem no século XVI com finalidade militar e apenas em 1909 foram iniciadas as obras de melhoramento e de construção do porto para fins comerciais (ALMEIDA, 2000). O porto do Recife está estruturalmente consolidado e inserido em uma área totalmente urbana.

Já o porto de SUAPE foi construído com o objetivo de ter uma estrutura adequada para servir como porto industrial complementar ao porto do Recife, em uma área com capacidade de se expandir, apesar de estar inserido em um rico ecossistema.

O Complexo Industrial Portuário de Suape (CIPS) também denominado Complexo Industrial Portuário Governador Eraldo Gueiros - SUAPE está situado nos municípios de Ipojuca e Cabo de Santo Agostinho, no litoral sul do Estado de Pernambuco. A sua área total ocupada é de 13.500 hectares, distribuídos em Zonas Portuária, Industrial, Administrativa, de Preservação Ecológica e Cultural (SUAPE, 2008).

Situado a $40 \mathrm{~km}$ ao sul do Recife, Suape é o principal porto de toda região Nordeste do Brasil. Contempla um mercado consumidor com 50 milhões de habitantes e um PIB de US\$ 110 bilhões. Suape, situado na extremidade oriental da Costa Atlântica da América do Sul, possui localização estratégica em relação às principais rotas marítimas de navegação, conectando-se com mais de 160 portos em todos os continentes, o que o coloca em condições de ser um dos principais portos concentradores de cargas - hub port no Atlântico Sul.

Ao ser concebido na forma de "porto-indústria", oferece condições para instalação de empreendimentos industriais. A infraestrutura terrestre do Complexo Industrial dispõe de $50 \mathrm{~km}$ de rodovias e $41 \mathrm{~km}$ de ferrovias próprias, com acesso direto ao terminal de contêineres, ao parque de tancagem de granéis líquidos, de minérios e aos Cais Públicos 1 e 4.

O porto de Suape dispõe ainda do fornecimento de gás natural, energia elétrica e água bruta e tratada. O seu licenciamento ambiental foi concedido desde 1999 (PIRES ADVOGADOS \& CONSULTORES, 2000), disponibilizando $45 \%$ de sua área à preservação ambiental de acordo com o Plano de Desenvolvimento e Zoneamento (PDZ).

Ainda que nos dias de hoje o porto representa, na visão desenvolvimentista, um benefício sócio-econômico, os impactos ambientais com a construção do porto e do terminal de tancagem revelaram-se desastrosos.

Dentre eles, a obstrução do rio Ipojuca que transformou o estuário em uma laguna costeira, com rítmos variáveis de marés trouxe consequências graves para a região que foram estudados e apresentadas por Neumann na sua Tese de doutorado em 1994.

Diante destas peculiaridades, desenvolveu-se a análise comparativa entre os dois portos e os desafios específicos para a gestão ambiental.

\section{MATERIAL E MÉTODOS}

A presente pesquisa foi realizada dentro de uma abordagem qualitativa, utilizandose a metodologia interativa visando facilitar o entendimento dos dados coletados. Dessa forma, com a metodologia interativa foi possível analisar e comparar as características da gestão ambiental portuária na área de estudo nas três fases detalhadas na metodologia: na pré-análise, na exploração do material e no tratamento dos resultados.

O referencial teórico utilizado como suporte para a compreensão do tema objeto deste estudo, aprofundou-se na pesquisa quanto ao histórico do sistema portuário brasileiro para entendimento do contexto em que se insere. Identificando-se os principais instrumentos do sistema portuário complementado por outros instrumentos de gestão mais recentes, porém também importantes a sua avaliação.

Os procedimentos metodológicos que orientaram o desenvolvimento da pesquisa foram fundamentados nas definições e considerações baseados no conhecimento construído, no método e na abordagem qualitativa. Em seguida desenvolveu-se o 
SÁ, M. E. M.; LEAL NETO, A. de C.; Florencio, L. Síntese da análise comparativa entre os portos do Recife e de SUAPE: desafios para a gestão ambiental.

processo de codificação dos dados na classificação das categorias teóricas e empíricas e na sistematização das unidades de análise.

O conhecimento construído embasado na investigação científica e disciplinado pelo método garantiu a construção do pensamento desta pesquisa que iniciou com o problema da gestão ambiental nos portos do estado de Pernambuco e que foi concluída com um produto capaz de dar origem a novas interrogações.

Desta forma, a opção escolhida neste estudo foi por uma abordagem qualitativa, tomando como referencial a metodologia interativa de Oliveira (2008) com algumas adaptações que foram realizadas para melhor atender aos objetivos pré-estabelecidos no desenvolvimento deste trabalho facilitando a compreensão da realidade em sua dinâmica.

Uma vez que na pesquisa realizada por Oliveira (2005), a utilização isolada de um método não atendeu ao objeto de estudo, Oliveira (2005), decidiu por interagir a técnica de coleta de dados do Círculo Hermenêutico-Dialético (CHD) de Guba e Lincoln (1989) e o método de Análise Hermenêutica-Dialética (AHD) de Minayo (1998), para uma análise mais profunda da fala e dos depoimentos.

Esta interação permitiu reduzir de forma significativa a subjetividade, tanto no processo de coleta de dados, como na análise dos mesmos, onde os atores através de suas falas possibilitaram compreender a realidade. Sendo este o mesmo caminho adotado no desenvolvimento desta pesquisa.

Analisou-se o histórico da trajetória do sistema portuário brasileiro para tornar possível o entendimento de sua relação com o mundo globalizado e com a política ambiental brasileira para o setor dos transportes, com ênfase no subsetor portuário sempre relacionando seus princípios com a evolução da política ambiental nacional e internacional.

Destarte, a construção do conhecimento adotou uma postura holística e sistêmica compatível com a gestão ambiental que é dinâmica e se desenvolve dentro de um processo dialético.

Por sua vez, a categorização dos dados nesse procedimento metodológico se configura como um processo que exige o máximo de atenção na sua configuração, tanto na codificação dos dados realizando uma revisão rigorosa, quanto na classificação das categorias.

Portanto, os instrumentos de gestão ambiental portuária foram estudados e interpretados de forma sistêmica, com base na fundamentação teórica, para poder estruturar as categorias gerais ou teóricas que nortearam os roteiros do questionário aplicado e as entrevistas realizadas aos dois grupos selecionados para amostra da pesquisa, que foi composta por quatro profissionais envolvidos na gestão ambiental de cada um dos dois portos de acordo com a representação da figura 1.

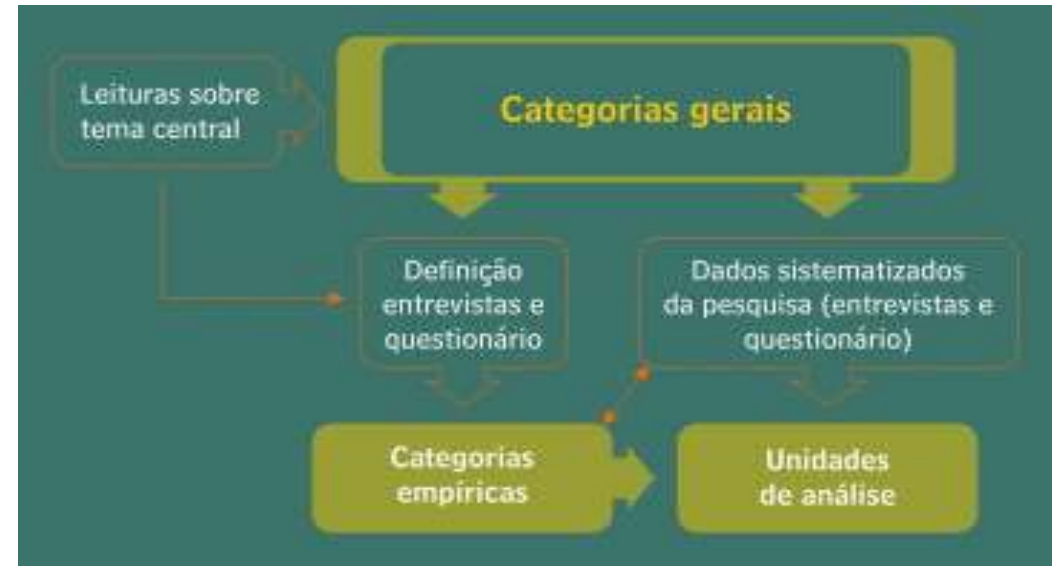

Tropical Oceanography, Recife, v. 39, n. 2, p. 107-122, 2011. 
SÁ, M. E. M.; LEAL NETO, A. de C.; Florencio, L. Síntese da análise comparativa entre os portos do Recife e de SUAPE: desafios para a gestão ambiental.

FIGURA 1 - Categorias de análise

Fonte: Adaptado de OLIVEIRA, 1999.

A técnica de coleta de dados do CHD é considerada um processo hermenêutico porque tem caráter interpretativo e é dialético porque implica em comparação e contraste de diferentes pontos de vista, objetivando um alto nível de síntese representado na figura 2 .

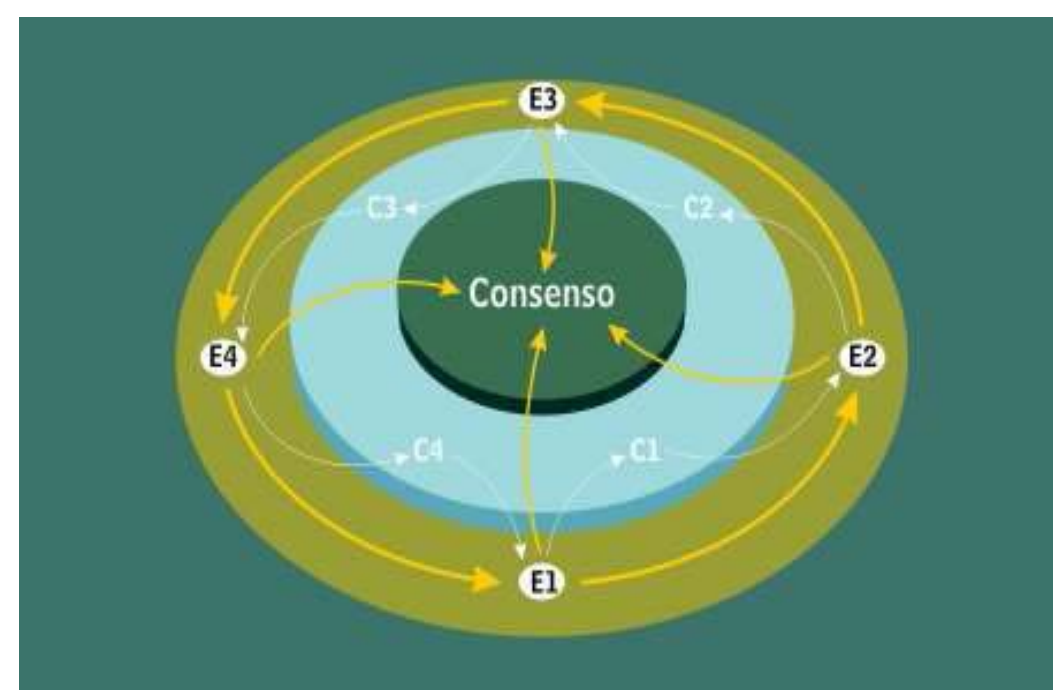

FIGURA 2 - Circulo Hermenêutico-Dialético

Fonte: Adaptado de Caraciolo, 2008.

Em seguida as sínteses das entrevistas e obtido "o consenso", este entendido como a aproximação mais perto possível de retratar a realidade para cada grupo de entrevistados, foi realizada também uma triangulação entre os dados quantitativos e qualitativos e fechado o ciclo mais próximo ainda da realidade obtendo assim consistência no estudo.

Desta forma, as categorias gerais ou teóricas identificadas serviram como referencial para a determinação das categorias empíricas ou subcategorias.

A identificação das unidades de análise foi viabilizada pela sistematização dos dados obtidos na pesquisa e nas entrevistas aplicando-se a técnica do CHD, em triangulação com o questionário, com as observações nos portos e com a documentação disponibilizada.

Diante desse cruzamento de dados, a análise final dos resultados foi conduzida com mais segurança e foram elaboradas as Matrizes Gerais para o Porto do Recife e para o Porto de SUAPE que passaram a ser os novos objetos de análise da pesquisa indicados respectivamente nos quadros 1 e 2 e apresentadas neste artigo no item Resultados e Discussão.

Enfim, após a elaboração das Matrizes Gerais foi iniciada a Metodologia da Análise Hermenêutica-Dialética (AHD) para aprofundar a análise na comparação dos quadros referentes às categorias empíricas entre os resultados dos dois portos quanto as suas gestões ambientais apresentadas na figura 3. 


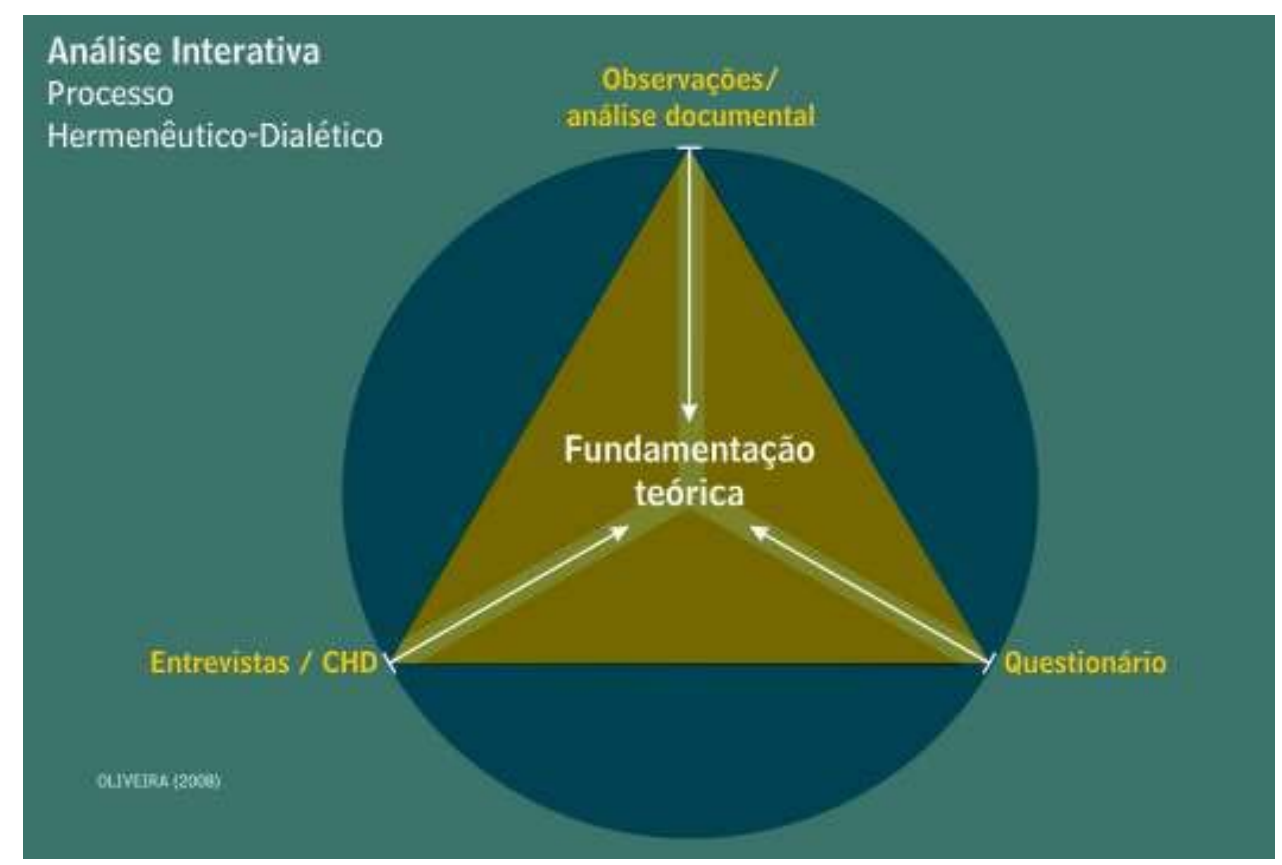

FIGURA 3 - Análise Interativa Processo Hermenêutico-Dialético

Fonte: Adaptado de OLIVEIRA, 2008

\section{RESULTADOS E DISCUSSÃO}

Observou-se que os portos possuem características ambientais e operacionais específicas bem distintas e que os resultados encontrados nesta pesquisa oferecem subsídios para ajudar as administrações portuárias pesquisadas a implementarem suas Agendas Ambientais Portuárias (AAP) como instrumento de planejamento participativo.

O suporte à análise dos dados necessário para o início da construção do conhecimento foi adquirido com o uso da técnica do Círculo Hermenêutico-Dialético (CHD) com base na pesquisa bibliográfica, análise documental, pesquisa a documentos disponíveis na internet, aplicação de questionário, e na consolidação das entrevistas.

Os principais instrumentos de gestão ambiental portuária abordados nesta pesquisa contribuíram para evidenciar quais os instrumentos realmente implementados nos portos nacionais e internacionais, além de subsidiar a identificação dos principais desafios e conflitos da gestão ambiental portuária que deveriam ser aprofundados com a metodologia escolhida para o estudo.

Assim, depois de conhecê-los, foi possível estruturar as categorias gerais ou teóricas que mais se relacionam com as dificuldades na execução da GAP dos dois portos, sem sair do contexto mundial real.

Essas leituras convergentes possibilitaram a identificação das seguintes categorias gerais ou teóricas, que por suas abrangências, importância e urgência coincidiram com os mesmos instrumentos adotados pela agência reguladora ANTAQ (2008), na avaliação dos portos nacionais quanto à gestão ambiental: 1. Núcleo Ambiental, 2. Gerenciamento de Riscos de Poluição, 3. Gerenciamento de Resíduos Sólidos e 4. Auditoria Ambiental.

As categorias gerais ou teóricas identificadas nortearam as perguntas do questionário aplicado e os roteiros das entrevistas realizadas. Essas categorias gerais ou teóricas, juntamente com as questões formuladas para o questionário e o roteiro das entrevistas, serviram como referencial para a determinação das seguintes categorias empíricas ou subcategorias detalhadas nos Quadros de 3 a 6.

A identificação das unidades de análise foi viabilizada pela sistematização dos dados obtidos na pesquisa e nas entrevistas aplicando-se a técnica do CHD já relatada, em 
triangulação com o questionário, além das observações nos portos e da documentação disponibilizada.

Desta forma, com esse cruzamento de dados, a análise final dos resultados foi conduzida com mais segurança e foram elaboradas as matrizes gerais para os dois portos relacionando as categorias gerais ou teóricas, as categorias empíricas ou subcategorias e as unidades de análise apresentadas nos QUADROS 1 e 2 que passaram a ser os novos objetos de análise da pesquisa.

QUADRO 1 - Matriz geral das categorias (Porto do Recife)*

*Os títulos em cada coluna (Núcleo Ambiental, etc.) são as categorias gerais ou teóricas; os itens numerados abaixo de cada título representam as categorias empíricas ou subcategorias; os itens com marcadores dizem respeito às unidades de análise ou conteúdo/resultados das entrevistas (2008).

\begin{tabular}{|c|c|c|c|}
\hline $\begin{array}{l}1 \text { Núcleo } \\
\text { Ambiental }\end{array}$ & $\begin{array}{l}2 \text { Gerenciamento } \\
\text { de Riscos de } \\
\text { Poluição }\end{array}$ & $\begin{array}{l}\text { Gerenciamento de } \\
\text { Resíduos Sólidos }\end{array}$ & $\begin{array}{l}4 \text { Auditoria } \\
\text { Ambiental }\end{array}$ \\
\hline $\begin{array}{l}\text { 1.1 Núcleo } \\
\text { Ambiental } \\
\text { - Criado em } \\
\text { fevereiro de } 2007\end{array}$ & $\begin{array}{l}\text { 2.1 Manual de } \\
\text { Procedimento } \\
\text { Interno } \\
\text { - Não possui }\end{array}$ & $\begin{array}{l}\text { 3.1 Plano de } \\
\text { Gerenciamento de } \\
\text { Resíduos Sólidos- } \\
\text { PGRS } \\
\text { - Possui PGRS } \\
\text { implantado, não } \\
\text { aprovado pela ANVISA }\end{array}$ & $\begin{array}{l}\text { 4.1 Sistema de } \\
\text { Gestão Ambiental } \\
\text { (SGA) } \\
\text { - Não possui }\end{array}$ \\
\hline $\begin{array}{l}\text { 1.2 Perfil } \\
\text { Profissional } \\
\text { - capacitação } \\
\text { prevista } \\
\text { - } \quad \text { Núcleo com } \\
\text { apenas } 2 \text { técnicos } \\
\text { - } 1 \text { é do quadro } \\
\text { efetivo }\end{array}$ & $\begin{array}{l}\text { 2.2 Plano de } \\
\text { Emergência (PEI) } \\
\text { - Possui PEI } \\
\text { aprovado } \\
\text { - Não implantado, } \\
\text { será revisado }\end{array}$ & $\begin{array}{l}\text { 3.2 Instalações } \\
\text { próprias para coleta, } \\
\text { triagem e destinação } \\
\text { - Possui }\end{array}$ & \begin{tabular}{|l} 
4.2 Auditoria \\
Ambiental \\
• Realizada em \\
2005
\end{tabular} \\
\hline $\begin{array}{l}\text { 1.3 Processo de } \\
\text { Decisão } \\
\text { - Influência } \\
\text { restrita } \\
\text { - Não participa } \\
\text { do CAP }\end{array}$ & $\begin{array}{l}\text { 2.3 Manual de } \\
\text { Procedimento } \\
\text { Interno e PEI } \\
\text { - Articulação com } \\
\text { os Arrendatários } \\
\text { iniciada } \\
\text { - Levantamento de } \\
\text { existência dos PEIs }\end{array}$ & & $\begin{array}{l}\text { 4.3 Cronograma do } \\
\text { Plano de Ação } \\
\text { - Gradualmente } \\
\text { atendendo }\end{array}$ \\
\hline
\end{tabular}

QUADRO 2 - Matriz geral das categorias (Porto de SUAPE)*

*Os títulos em cada coluna (Núcleo Ambiental, etc.) são as categorias gerais ou teóricas; os itens numerados abaixo de cada título representam as categorias empíricas ou subcategorias; os itens com marcadores dizem respeito às unidades de análise ou conteúdo/resultados das entrevistas (2008). 
SÁ, M. E. M.; LEAL NETO, A. de C.; Florencio, L. Síntese da análise comparativa entre os portos do Recife e de SUAPE: desafios para a gestão ambiental.

\begin{tabular}{|c|c|c|c|}
\hline $\begin{array}{l}1 \text { Núcleo } \\
\text { Ambiental }\end{array}$ & $\begin{array}{l}2 \text { Gerenciamento } \\
\text { de Riscos de } \\
\text { Poluição }\end{array}$ & $\begin{array}{l}\text { 3 Gerenciamento } \\
\text { de Resíduos Sólidos }\end{array}$ & $\begin{array}{l}4 \text { Auditoria } \\
\text { Ambiental }\end{array}$ \\
\hline $\begin{array}{l}\text { 1.1 Núcleo } \\
\text { Ambiental } \\
\text { - Criado em } \\
\text { janeiro de } 2007\end{array}$ & $\begin{array}{l}\text { 2.1 Manual de } \\
\text { Procedimento } \\
\text { Interno } \\
\text { - Não possui }\end{array}$ & $\begin{array}{l}\text { 3.1 Plano de } \\
\text { Gerenciamento de } \\
\text { Resíduos Sólidos- } \\
\text { PGRS } \\
\text { - Possui PGRS } \\
\text { submetido à CPRH } \\
\text { - Precisa ser } \\
\text { adaptado a nova } \\
\text { realidade de Suape }\end{array}$ & $\begin{array}{l}\text { 4.1 Sistema de } \\
\text { Gestão Ambiental } \\
\text { (SGA) } \\
\text { - Não possui }\end{array}$ \\
\hline $\begin{array}{l}\text { 1.2 Perfil } \\
\text { Profissional } \\
\text { - capacitação } \\
\text { prevista } \\
\text { - Multidisciplinar } \\
5 \text { téc. nível } \\
\text { superior. }\end{array}$ & $\begin{array}{l}\text { 2.2 Plano de } \\
\text { Emergência (PEI) } \\
\text { - Possui PEI em } \\
\text { análise } \\
\text { - Não implantado, } \\
\text { será revisado. }\end{array}$ & $\begin{array}{l}\text { 3.2 Instalações } \\
\text { próprias para } \\
\text { coleta, triagem e } \\
\text { destinação } \\
\text { - Possui, porém } \\
\text { insatisfatória }\end{array}$ & $\begin{array}{l}\text { 4.2 Auditoria } \\
\text { Ambiental } \\
\text { - } \quad \text { Realizada em } 2003\end{array}$ \\
\hline $\begin{array}{l}\text { 1.3. Processo de } \\
\text { Decisão } \\
\text { - Influência } \\
\text { ampla, mas não } \\
\text { total } \\
\text { Participa do CAP }\end{array}$ & $\begin{array}{l}\text { 2.3 Manual de } \\
\text { Procedimento } \\
\text { Interno e PEI } \\
\text { - Articulação com } \\
\text { os Arrendatários } \\
\text { iniciada } \\
\text { Levantamento de } \\
\text { existência dos PEIs }\end{array}$ & & $\begin{array}{l}\text { 4.3. Cronograma do } \\
\text { Plano de Ação } \\
\text { - Não atendeu } \\
\text { - Desconsiderado } \\
\text { pela discordância com } \\
\text { auditoria realizada }\end{array}$ \\
\hline
\end{tabular}

Após a condensação dos dados, foram obtidas três categorias empíricas para a Categoria Teórica 1 - Núcleo Ambiental (apresentadas no Quadro 3):

1.1. Criação do Núcleo Ambiental;

1.2. Perfil profissional da equipe e

1.3. Processo de decisão.

QUADRO 3 - Comparação na Categoria Teórica 1. Núcleo Ambiental (2008).

\begin{tabular}{|c|c|c|c|}
\hline \multirow[b]{2}{*}{ 1. NÚCLEO AMBIENTAL } & \multicolumn{2}{|c|}{ AMOSTRAS DO ESTUDO } & \multirow[b]{2}{*}{ Observações } \\
\hline & $\begin{array}{c}\text { PORTO DO } \\
\text { RECIFE }\end{array}$ & $\begin{array}{c}\text { PORTO DE } \\
\text { SUAPE }\end{array}$ & \\
\hline
\end{tabular}




\begin{tabular}{|c|c|c|c|}
\hline CRIAÇÃO & criado & criado & \\
\hline \multicolumn{4}{|c|}{ 1.2 PERFIL PROFISSIONAL } \\
\hline CAPACITAÇÃO & Planejada & Planejada & \\
\hline FORMAÇÃO DO NÚCLEO & Insuficiente & $\begin{array}{l}\text { Quase } \\
\text { Suficiente }\end{array}$ & \\
\hline $\begin{array}{l}\text { TIPO DE CONTRATO } \\
\text { PROFISSIONAL }\end{array}$ & Algum efetivo & $\begin{array}{l}\text { Nenhum } \\
\text { efetivo }\end{array}$ & \\
\hline \multicolumn{4}{|c|}{ 1.3 PARTICIPAÇÃO NO PODER DECISÓRIO } \\
\hline INFLUÊNCIA & $\begin{array}{l}\text { Influência } \\
\text { Restrita }\end{array}$ & $\begin{array}{l}\text { Ampla } \\
\text { Influência }\end{array}$ & \\
\hline PARTICIPAÇÃO NO CAP & $\begin{array}{l}\text { Não participa } \\
\text { do CAP }\end{array}$ & $\begin{array}{l}\text { Participa do } \\
\text { CAP }\end{array}$ & $\begin{array}{l}\text { CAP- Conselho de } \\
\text { Autoridade Portuária }\end{array}$ \\
\hline
\end{tabular}

A análise deste Quadro 3 foi voltada à obtenção do conhecimento do processo de formação dos Núcleos Ambientais nos portos pesquisados. Percebeu-se que a época de criação é praticamente a mesma, ou seja, o início da atual gestão governamental estadual em 2007.

Ao analisar o cruzamento dos dados, constatou-se que anteriormente a 2007 existia uma Gerência de Meio Ambiente e Engenharia no Porto do Recife, que atendia as duas áreas, e em Suape havia uma Coordenadoria de Meio Ambiente e Engenharia, mas que os técnicos eram "utilizados" para suprir outras áreas e não trabalhavam diretamente com a gestão ambiental.

Entretanto, desde o início de 2007, os dois portos estão seguindo as determinações identificadas no referencial teórico quanto ao atendimento à Resolução CIRM 06/98, que requer a criação do Núcleo também recomendado pela ANTAQ (2008) e por Porto \& Teixeira (2002), que consideram o Núcleo fundamental para a gestão ambiental.

Esta categoria empírica do Quadro 3 surgiu da necessidade de analisar a composição do Núcleo Ambiental quanto ao perfil profissional da equipe, a sua capacitação, multidisciplinaridade e o seu vínculo profissional.

Ao analisar este Quadro 3, percebe-se que os dois portos prevêem alguma capacitação para o núcleo. No porto do Recife, o núcleo possui apenas 2 técnicos de nível superior, apesar de formações profissionais diferentes. Possui uma vantagem, porém, em relação ao porto de Suape, uma vez que um dos dois técnicos pertence ao quadro efetivo, enquanto que no porto de Suape os cinco técnicos de nível superior que formam a equipe do núcleo multidisciplinar não fazem parte do quadro.

A direção do Porto de Suape está buscando estimular a capacitação, mesmo não existindo um programa definido com este propósito.

A categoria teórica de Gerenciamento de Riscos de Poluição, ao ser condensada, conduziu à identificação de três categorias empíricas, indicadas na Quadro 4:

2.1 Manual de Procedimento Interno;

2.2 Plano de Emergência (PEI) e

2.3 Manual de procedimento Interno (articulação).

Quadro 4 - Comparação dos dois portos na Categoria Teórica 2. Gerenciamento de Riscos de Poluição (2008). 
SÁ, M. E. M.; LEAL NETO, A. de C.; Florencio, L. Síntese da análise comparativa entre os portos do Recife e de SUAPE: desafios para a gestão ambiental.
2. GERENCIAMENTO
DE RISCOS DE
POLUIÇÃO
AMOSTRAS DO ESTUDO
PORTO DO
PORTO DE
Observações
RECIFE
SUAPE

\subsection{MANUAL DE PROCEDIMENTO INTERNO}

\begin{tabular}{|l|l|l}
\hline CRIAÇÃo & Não possui & Não possui \\
\hline
\end{tabular}

2.2 PLANO DE EMERGÊNCIA INDIVIDUAL (PEI)

\begin{tabular}{l|c|c|c}
\hline EXISTÊNCIA & $\begin{array}{c}\text { Possui e } \\
\text { aprovado }\end{array}$ & $\begin{array}{c}\text { Possui em } \\
\text { análise }\end{array}$ & \\
\hline IMPLEMENTAÇÃo & $\begin{array}{c}\text { Não } \\
\text { implementado }\end{array}$ & $\begin{array}{c}\text { Não } \\
\text { implementado }\end{array}$ & \\
\hline
\end{tabular}

2.3 MANUAL DE PROCEDIMENTO INTERNO E PEI (ARTICULAÇÃO COM OS ARRENDATÁRIOS)

\begin{tabular}{l|c|c|l}
\hline EXISTÊNCIA & $\begin{array}{c}\text { Não existe } \\
\text { articulação }\end{array}$ & $\begin{array}{c}\text { Não existe } \\
\text { articulação }\end{array}$ & \\
\hline ARTICULAÇÃo & $\begin{array}{c}\text { Arrendatários } \\
\text { sem MPI e sem } \\
\text { PEI }\end{array}$ & $\begin{array}{c}\text { Arrendatários } \\
\text { sem MPI e sem } \\
\text { PEI }\end{array}$ & $\begin{array}{l}\text { MPI - Manual de } \\
\text { Procedimentos } \\
\text { Internos PEI - Plano } \\
\text { de Emergência } \\
\text { Individual }\end{array}$ \\
\hline
\end{tabular}

Ao analisar a situação dos portos estudados, para conhecer o atendimento à legislação quanto à existência do Manual de Procedimento Interno, percebeu-se que existe a preocupação com a situação atual, com a importância do Gerenciamento de Risco de Poluição, e que providências estão sendo adotadas para o seu atendimento, conforme explicitado pelos depoimentos dos profissionais entrevistados do Porto do Recife e do Porto de Suape.

Apesar de previsto na Lei no 9966/00 (Lei do óleo), e na MARPOL 73/78, comprovou-se que os portos do Recife e de Suape não elaboraram os Manuais de Procedimentos Internos como a maioria dos portos nacionais, conforme a avaliação da ANTAQ (2008).

Ao analisar o Quadro 4, na busca de conhecer a situação dos portos estudados quanto à existência dos Planos de Emergência Individual (PEI) e a situação de conformidade com a legislação anteriormente comentada no referencial teórico, percebeu-se que a situação dos dois portos é semelhante: ambos realizaram os PEIs, foram submetidos à análise (o do Porto do Recife foi aprovado), não foram implantados e serão revisados em curto prazo.

Esta categoria foi também utilizada para verificar a articulação entre as autoridades portuárias e os terminais e/ou arrendatários quanto aos Manuais de Procedimentos Internos e PEIs, onde se verificou que não existe ainda articulação nos dois portos e que ambos estão realizando levantamentos dos terminais e/ou arrendatários se possuem Manuais de Procedimentos Internos e/ou PEIs.

Desta forma, o gerenciamento de riscos de poluição nos portos de Pernambuco também acompanha a tendência nacional conforme abordado pela ANTAQ (2008), além de ter sido também constatado que em grande parte dos portos organizados, existe um acordo com a PETROBRAS, que possui estrutura para atendimento de emergências nos chamados Centros de Defesa Ambiental (CDAs), como enfatizado pelos entrevistados de Suape. 
SÁ, M. E. M.; LEAL NETO, A. de C.; Florencio, L. Síntese da análise comparativa entre os portos do Recife e de SUAPE: desafios para a gestão ambiental.

$\mathrm{Na}$ categoria teórica de Gerenciamento de Resíduos Sólidos, mediante a condensação dos dados foram identificadas duas categorias empíricas, de acordo com o QUADRO 5:

3.1 Existência do Plano de Gerenciamento de Resíduos Sólidos (PGRS) e

3.2 Existência de instalações próprias para coleta, triagem e destinação final.

QUADRO 5 - Comparação dos dois portos na Categoria Teórica 3. Gerenciamento de Resíduos Sólidos (2008).

3. GERENCIAMENTO

DE RESÍDUOS

SÓLIDOS

RECIFE

\subsection{PLANO DE GERENCIAMENTO DE RESÍDUOS SÓLIDOS (PGRS)}

\section{AMOSTRAS DO ESTUDO}

\section{PORTO DE}

SUAPE
OBSERVAÇÕES
EXISTÊNCIA
Possui PGRS implantado e não aprovado
Possui PGRS em

análise e não

implantado

\subsection{INSTALAÇÃO PRÓPRIA PARA COLETA,TRIAGEM E DESTINAÇÃO}

\begin{tabular}{|l|l|l|l}
\hline EXISTÊNCIA & Possui & Possui & $\begin{array}{l}\text { PGRS - Plano } \\
\text { de Gerenciamento de } \\
\text { Resíduos Sólidos }\end{array}$ \\
\hline
\end{tabular}

Ao analisar este Quadro 5, em busca da identificação da existência do Plano de Gerenciamento dos Resíduos Sólidos e do atendimento à legislação, verificou-se um diferencial entre os dois portos. Enquanto o Porto do Recife possui o PGRS implantado, mas não aprovado pela ANVISA, o Porto de Suape possui o PGRS que se encontra em análise na $\mathrm{CPRH}$, por ser um complexo portuário industrial, mas que ainda não foi implantado.

Os PGRS dos dois portos, porém, serão revisados. Percebeu-se nas entrevistas que os dois portos possuem dificuldades de articulação com os terminais e arrendatários em relação ao gerenciamento dos resíduos gerados.

Por outro lado, para o Complexo Industrial Portuário de Suape (CIPS), verificou-se com os depoimentos dos entrevistados, a dificuldade em identificar o tratamento e a destinação final adequados, uma vez que quando o CIPS foi projetado não havia sido planejado para tratar todos os resíduos gerados no complexo de forma integrada.

Os entrevistados demonstraram que os responsáveis pela gestão ambiental dos portos estudados conhecem suas obrigações legais e buscam o atendimento às conformidades de acordo com o que foi apresentado no referencial teórico.

A categoria geral ou teórica referente à Auditoria Ambiental foi escolhida por ser a mais abrangente da gestão, por ela ser a essência do processo de gestão ambiental e por permitir a avaliação do funcionamento do SGA.

A condensação das informações conduziu à identificação de três categorias empíricas, apresentadas no QUADRO 6:

4.1 Existência do Sistema de Gestão Ambiental,

4.2 Realização de Auditoria Ambiental e

4.3 Situação do cumprimento do Cronograma do Plano de Ação.

QUADRO 6: Comparação dos dois portos na Categoria Teórica 4. Auditoria Ambiental (2008). 
SÁ, M. E. M.; LEAL NETO, A. de C.; Florencio, L. Síntese da análise comparativa entre os portos do Recife e de SUAPE: desafios para a gestão ambiental.

4. AUDITORIA

AMBIENTAL

AMOSTRAS DO ESTUDO

PORTO DO RECIFE

Observações

SUAPE

\subsection{SISTEMA DE GESTÃO AMBIENTAL (SGA)}

\begin{tabular}{|l|l|l}
\hline EXISTÊNCIA & Não possui & Não possui \\
\hline
\end{tabular}

\subsection{AUDITORIA AMBIENTAL}

\begin{tabular}{l|l|l|l}
\hline REALIZAÇÃO & Realizada & Realizada & \\
\hline
\end{tabular}

\subsection{CRONOGRAMA DE AÇÃO}

\begin{tabular}{l|c|c|c}
\hline CUMPRIMENTO & Não cumpriu & Não cumpriu & \\
\hline EXECUÇÃO & $\begin{array}{c}\text { Parcialmente } \\
\text { atendido }\end{array}$ & Não atendido & \\
\hline
\end{tabular}

Esta categoria empírica surgiu da necessidade de se conhecer quais as percepções dos entrevistados quanto às dificuldades de implantação de um sistema de gestão ambiental.

Com o intuito de analisar o entendimento dos entrevistados quanto à importância da realização de auditorias ambientais, observou-se que a percepção da importância está mais voltada ao atendimento da legislação do que aos benefícios decorrentes das auditorias.

As afirmações observadas nos depoimentos revelaram ainda de forma mais acentuada a preocupação em realizar a auditoria para atender as exigências da Licença de Operação (LO), apesar de os entrevistados acharem que, à medida que estão atendendo às exigências legais, estão também preocupados com a gestão ambiental e agindo corretamente e de uma forma pró-ativa de acordo com os posicionamentos dos profissionais entrevistados.

As dificuldades encontradas nos dois portos foram comparadas com as dificuldades dos demais portos brasileiros e da comunidade européia, revelando-se semelhantes quanto aos custos envolvidos, quanto ao fato da proteção ambiental não ser considerada prioridade, quanto à falta de treinamento e também em relação à multiplicidade de agências responsáveis pela proteção ambiental (ESPO, 2005).

Os resultados revelaram que seus gestores estão empenhados em atender às exigências e condicionantes ambientais, embora existam dificuldades técnicas, políticas e de definição de prioridades de investimento, que ainda dificultam a sua implementação.

Discussão quanto à metodologia: A realização deste estudo utilizando-se a metodologia interativa se desenvolveu em um processo dialético compatível com a gestão ambiental que é uma realidade dinâmica em construção e permitiu alcançar os objetivos de diagnosticar as características das conformidades ambientais específicas dos portos do Recife e de SUAPE e identificar os procedimentos adotados pelos gestores para atendê-las.

A pesquisa realizada evidencia que, o processo de gestão ambiental portuária é uma realidade em construção em todos os principais portos do mundo e mais especificamente nos portos brasileiros onde ainda há muito que se fazer para a execução de uma gestão ambiental eficaz conforme ressaltado por Porto \& Teixeira (2002). 
SÁ, M. E. M.; LEAL NETO, A. de C.; Florencio, L. Síntese da análise comparativa entre os portos do Recife e de SUAPE: desafios para a gestão ambiental.

Discussão quanto ao referencial teórico: $O$ referencial teórico abordado proporcionou o arcabouço necessário para a contextualização da gestão ambiental do setor de transporte portuário mundial, nacional e regional. Mostrou-se adequado para a consecução dos objetivos da pesquisa e principalmente na construção do conhecimento.

Diante dos instrumentos de Gestão pesquisados pode-se dizer que o referencial teórico ofereceu suporte à análise dos dados e à avaliação dos principais instrumentos de gestão ambiental portuária e subsidiou a escolha dos instrumentos mais adequados para a realidade dos portos estudados.

Discussão quanto aos objetivos da pesquisa: Ao analisar as conformidades ambientais de cada um dos dois portos, constatou-se que apesar dos impactos potenciais se apresentarem completamente diferentes, as conformidades ambientais a serem atendidas são semelhantes.

Neste sentido, verificou-se e demonstrou-se na análise dos dados que o atendimento às exigências legais pelos dois portos ocorrem também de forma semelhante. Ambos estão com as licenças de operação da Agência Estadual de Meio Ambiente - $\mathrm{CPRH}$ vigentes e se esforçam em cumprir as exigências legais e os condicionantes do licenciamento.

Constatou-se a ausência de transversalidade na condução das questões ambientais que estão restritas ao núcleo ambiental e ao atendimento das exigências legais.

Estas constatações resultaram na identificação e na conclusão de que o desenvolvimento de uma Agenda Ambiental Portuária Institucional formalizará um compromisso ambiental da organização portuária assumido por todos que fazem parte do seu corpo organizacional e não se restringindo apenas ao Núcleo Ambiental.

Muito embora tenha sido identificado o atendimento à conformidade sobre a existência do Núcleo Ambiental percebeu-se a necessidade de capacitação ambiental não apenas para os que compõem o núcleo, mas também para outros setores da organização e para a diretoria.

Neste estudo foi abordada também a Avaliação Ambiental Estratégica (AAE) que se constitui o mais recente instrumento de gestão ambiental (PARTIDÁRIO, 2003). A literatura demonstra que é uma ferramenta fundamental na promoção de princípios e práticas de desenvolvimento sustentável. Entretanto, no setor portuário brasileiro este instrumento ainda foi pouco utilizado.

Nos dois portos pesquisados, identificou-se que a sensibilização para as questões ambientais iniciou-se recentemente. Provavelmente esse início foi em decorrência de leis ambientais mais rígidas e de um controle maior dos processos de licenciamento e de fiscalização.

Também se observou que entre os profissionais entrevistados não existia clareza sobre a importância da gestão ambiental, assim como para eles não existia evidência das diferenças entre gestão ambiental e o atendimento às exigências legais.

No estudo foi possível identificar as dificuldades para o atendimento às conformidades ambientais tornando-se evidente que poderiam ser equacionadas com um Sistema de Gestão Ambiental (SGA) eficaz.

Por outro lado, também houve a possibilidade de verificar que o desenvolvimento de uma Agenda Ambiental Portuária Institucional subsidiaria os passos a serem adotados na implementação do SGA, esclarecendo os papéis de cada setor e suas etapas, além de contribuir na mudança de cultura em relação aos cuidados ambientais que cada um deve ter.

Desta forma os resultados encontrados nesta pesquisa contribuem para o gerenciamento ambiental dos dois portos e subsidiam a identificação de ações para serem utilizadas como instrumentos de gestão ambiental estadual além de oferecerem 
SÁ, M. E. M.; LEAL NETO, A. de C.; Florencio, L. Síntese da análise comparativa entre os portos do Recife e de SUAPE: desafios para a gestão ambiental.

elementos para a implementação de suas Agendas Ambientais Portuárias como instrumento de planejamento participativo.

\section{CONCLUSÕES/RECOMENDAÇÕES}

Neste contexto e em um cenário globalizado, onde a gestão ambiental caminha no sentido de deixar a abordagem de controle da poluição para passar a abordagem estratégica de mercado, tendência que está sendo adotada para todos os portos, concluise que maior será a necessidade dos portos do Recife e de SUAPE implementarem seus SGAs e perseguirem a meta de no futuro próximo obter suas respectivas certificações.

Recomenda-se que a gestão ambiental seja abordada de forma estratégica nos portos do Recife e de SUAPE com o desenvolvimento das Agendas Ambientais Institucionais e/ou Locais. E por fim, conclui-se que esta pesquisa contribui para que os portos estudados atinjam o objetivo comum de segurança ambiental e vençam os desafios e as dificuldades para a implementação da Gestão Ambiental Portuária eficaz.

\section{REFERÊNCIAS}

ALMEIDA, Suely Cordeiro de. Um porto e uma cidade: fragmentos de história da cidade Recife dos Navios. Revista Symposium, Recife, ano 4, n. especial, p.25-37, jan./jun. 2000.

ANTAQ, Agência Nacional de Transportes Aquaviários. Panorama 2008 do Transporte Aquaviário - Avaliação da Gestão Ambiental nos portos organizados. Brasília: Secretaria Especial de Portos, 2008.

CARACIOLO, Patrícia Maria de Magalhães. A prática do reuso de águas: possibilidade de estímulo pela política nacional de recursos hídricos e de instrumento adicional de gestão. Dissertação de mestrado em Gestão e Políticas Ambientais. Universidade Federal de Pernambuco. 2008. 175 p.

ENGEVIX S.A., Estudos e Projetos de Engenharia. Cadastro das Instalações

Portuárias - Porto do Recife, Recife, Pernambuco, 1987.

ESPO, European Sea Ports Organisation. Environmental Survey 2004, 2005.

Disponível em:<http:// www.ecoports.com>. Acesso em: 30 de jul. de 2008.

GUBA, Egon S. \& LINCOLN, Yvonna S..Fourth generation evaluation. Newbury Park: Sage, 1989.

KITZMANN, D. \& ASMUS, M., Gestão ambiental portuária: desafios e possibilidades. Rio de Janeiro: Revista de Administração Pública (RAP) 40 (6): 104160, Nov. / Dez. 2006.

MINAYO, Maria Cecília de Souza. O desafio do conhecimento: pesquisa qualitativa em saúde: 5 ed. São Paulo: HUCITEC-ABRASCO, 1998. 269 p.

NEUMANN LEITÃO, Sigrid. Impactos antrópicos na comunidade zooplanctônica estuarina. Porto de Suape - PE. Tese de Doutorado, Escola de Engenharia de São Carlos, USP, São Paulo, 1994.

OliVeirA filHo, José Divard de, Adequação da Gestão Ambiental do Porto do

Recife à ISO 14.001:2004. Monografia de MBA Planejamento e Gestão Ambiental. Recife: FCAP/UPE, 2008.

OLIVEIRA, Maria Marly de. Projetos, Relatórios e textos na Educação Básica: como fazer. Petrópolis: Vozes, 2008.

OLIVEIRA, Maria Marly de. Como fazer pesquisa qualitativa. Recife: Bagaço, 2005.

OLIVEIRA, Maria Marly de. Formação em associativismo e desenvolvimento local no Nordeste do Brasil: a experiência de Camaragibe. 1999. 320 f. Tese (Doutorado em Educação) - Universidade de Sherbrooke, Quebec, Canadá, 1999. 
SÁ, M. E. M.; LEAL NETO, A. de C.; Florencio, L. Síntese da análise comparativa entre os portos do Recife e de SUAPE: desafios para a gestão ambiental.

PARTIDÁRIO, Maria do Rosário. Avaliação ambiental estratégica. Manual de apoio ao curso de Avaliação Ambiental Estratégica, Lisboa, Portugal, 2003.

PIRES ADVOGADOS \& CONSULTORES, Estudo de Impacto Ambiental - Suape/CIPS do Projeto Básico para Ampliação e Modernização do Porto de Suape. Recife, 2000.

PORTO, Marcos Maia e TEIXEIRA, Sérgio Grein. Portos e Meio Ambiente. São Paulo: Aduaneiras, 2002.

SEIFFERT, Maria Elizabete Bernardini. Gestão Ambiental: instrumentos, esferas de ação e educação ambiental. São Paulo: Atlas, 2007.

SUAPE, Complexo Industrial Portuário. Histórico. Disponível em:

http://www.suape.pe.gov.br. Acesso em: 13 de junho de 2008. 